\title{
World, Environment, Umwelt, and Inner-world: a Biological Perspective on Visual Awareness
}

\author{
Jan J. Koenderink ${ }^{a b}$ \\ ${ }^{a}$ Delft University of Technology, Department of Industrial Design, Landbergstraat 15, \\ 3584CS Delft, The Netherlands. ${ }^{b}$ University of Leuven (K.U. Leuven), Laboratory of \\ Experimental Psychology, Tiensestraat 102, 3000 Leuven, Belgium
}

\begin{abstract}
The world is all physical reality (Higgs bosons, and so forth), the environment is a geographical locality (your city, ...), the "Umwelt" is the totality of possible actions of the environment on the sensitive body surface of an agent (you, your dog, ...) and the possible actions of the agent on the environment (mechanical, chemical, ...), whereas the "inner-world" is what it is for the agent to be, that is awareness. Awareness is pre-personal, proto-conscious, and (perhaps) proto-rational. The various "worlds" described above are on distinct ontological levels. The world, and the environment are studied in the exact sciences, the Umwelt is studied by physiology and ethology. Ethology is like behavioristic psychology, with the difference that it applies to all animals. It skips the inner-world, e.g., it considers speech to be a mere movement of air molecules. The inner-world can only be known through first person reports, thus is intrinsically subjective. It can only be approached through "experimental phenomenology", which is based on intersubjectivity among humans. In this setting speech may perhaps mean something in addition to the movements of air molecules. These views lead to a model of vision as an "optical user interface". This has consequences for numerous applications.
\end{abstract}

Keywords: Umwelt, ecological niche, inner world, awareness, experimental phenomenology, user interfaces

\section{PRELIMINARIES}

Awareness is the rockbottom existence of sentient beings. ${ }^{1}$ It is pre-personal, proto-conscious, and perhaps proto-rational. Visual awareness is an important subpart of awareness. This is the human condition, for a dog a more important subpart might be olfactory awareness, for a bat it might be ultrasound awareness. This despite the fact that you, your dog, and the bat live in the same physical world, and in the same geographical environment. Your so-called "Umwelts" are different.

\subsection{The Notion of "Umwelt"}

The term "Umwelt" was introduced by Jakob von Uexküll, ${ }^{2}$ a Baltic-German biologist, active in the late nineteenth, and early twentieth centuries. It is a useful concept, quite different from the more common "physical world", "environment", or "ecological niche", concepts that are perhaps more familiar due to Gibson's work. ${ }^{3}$ The Umwelt is the world as it is relevant to an agent.

Von Uexküll was a remarkable figure who made considerable, lasting impact on biology, psychology and philosophy, but is all but forgotten now as an author, probably because he published in German. In my view he is important, because he showed how to steer clear of the barren road of behaviorism, yet approach (as a kind of limiting case) the "inner-world" of alien sentient beings scientifically. This has led to ethology, a successful sub-discipline of biology. ${ }^{4}$ A similar approach in psychology would approach experimental phenomenology. Unfortunately, experimental phenomenology is still suspect as perhaps not up to the expected standards of scientific rigor. As I discuss in this paper, there is really no reason to agree with this opinion of the learned community.

The Umwelt involves anything that may excite the sensitive body surface of the agent in a way that might cause it to react. Therefore ultrasound, electrical fields, and so forth, are not part of your Umwelt. Bats use

Send correspondence to j.j.koenderink@tudelft.nl

Human Vision and Electronic Imaging XVIII, edited by Bernice E. Rogowitz, Thrasyvoulos N. Pappas, Huib de Ridder,

Proc. of SPIE-IS\&T Electronic Imaging, SPIE Vol. 8651, 865103 • @ 2013 SPIE-IS\&T

CCC code: $0277-786 X / 13 / \$ 18 \cdot$ doi: $10.1117 / 12.2011874$

Proc. of SPIE Vol. $8651865103-1$ 


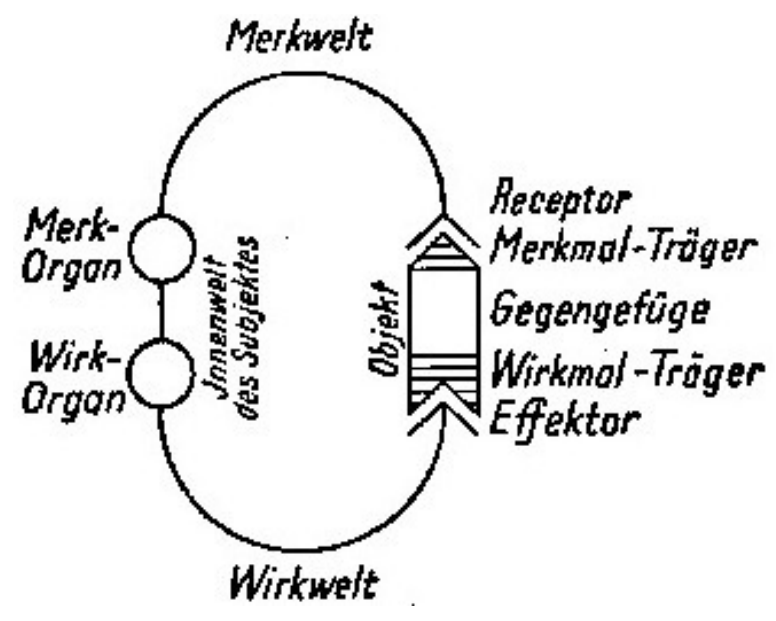

Figure 1. A figure from von Uexküll's Theoretische Biologie. It shows the most basic loop, running between Merkwelt (sense-world), at top, and Wirkwelt (action-world), at bottom. At left we find a specific Merkorgan, for instance, an eye, and a specific Wirkorgan, for instance, a muscle. At right, we find an Object (on the inner side), and Gegengefüge ("counterpart") at center right. At top and bottom right we find Receptor/Merkmal-Träger, and Effector/Wirkmal-Träger. This is the modern "sensori-motor-loop", well known in biology, psychology, AI, and robotics.

ultrasound, and sharks electric fields. They are alien to you in these respects. Von Uexküll calls this the Merkwelt (figure 1), meaning the world of processes that may stimulate the agent. I will use "sense-world". Of course, there exist various physical processes that do not fail to affect the body, yet do not give rise to immediate intentional reactions. For humans, examples are X-rays, radioactive fluxes, or ultraviolet solar radiation. These are not included in the sense-world, and thus are not part of the Umwelt.

Likewise, the Umwelt contains any way the organism may affect its world. You will usually do this through the use of your musculo-skeletal system, your voice, your glandular system, and so forth. Other agents (alien to you) may deploy entirely different ways of influencing the world. Just think of electric eels generating strong electric fields, quids spreading clouds of black ink, skunks emitting an offensive perfume, pit vipers injecting poisonous chemicals, or chameleons changing skin color. In view of such examples, humans have rather limited resources. Von Uexküll calls this the Wirkwelt (figure 1), meaning the world of possible actions open to the agent that might change its world. I will use "action-world".

The sense-world and action-world are connected in several ways. One way is through the physical environment. Actions generally lead to sensorial changes, due to the causal nexus of the physical world ("Laws of Physics"). Sensorial stimulation often leads to actions due to a system that is typical for the agent. Your nervous system is part of that. Thus the sense-world and the action-world are connected in a closed loop (or a nexus of intertwined loops) that involves both the agent and the world. This loop (including sense-world and action-world) is the backbone of the Umwelt, so to speak. In animals possessing sophisticated nervous systems, the nexus of loops is extremely complicated, even including different topologies. For instance, there tend to be loops that "shortcircuit" the environment, so-called re-afferences ${ }^{5}$ (figure 2). In such cases the brain runs simulations of the environment, so as to be able to predict prospective sensory inputs. The ability to simulate such performances as hand movements, or the effect of displacements of the body on optical input, must be crucial in the development of spatial awareness, and so forth.

Umwelts may be very simple, and not even contain "space" and "time" in any reasonable form, or be extremely rich, and sophisticated. The spectrum is huge. The "objects" that figure in the Umwelt are not necessarily those one might expect from an account of the physical structure of the environment. For instance, consider a scallop on the bottom of an undeep sea. It has eyes, and reacts to moving shadows by closing its shell, apparently to make it harder for predators to have an easy meal. To the scallop it makes no difference whether the moving shadow is caused by a passing ship, on the surface of the water, or a passing cloud, high up in the sky. Neither surface, sky, ship, nor cloud figure in the scallop's Umwelt. Only the moving shadows do. This evidently restricts 


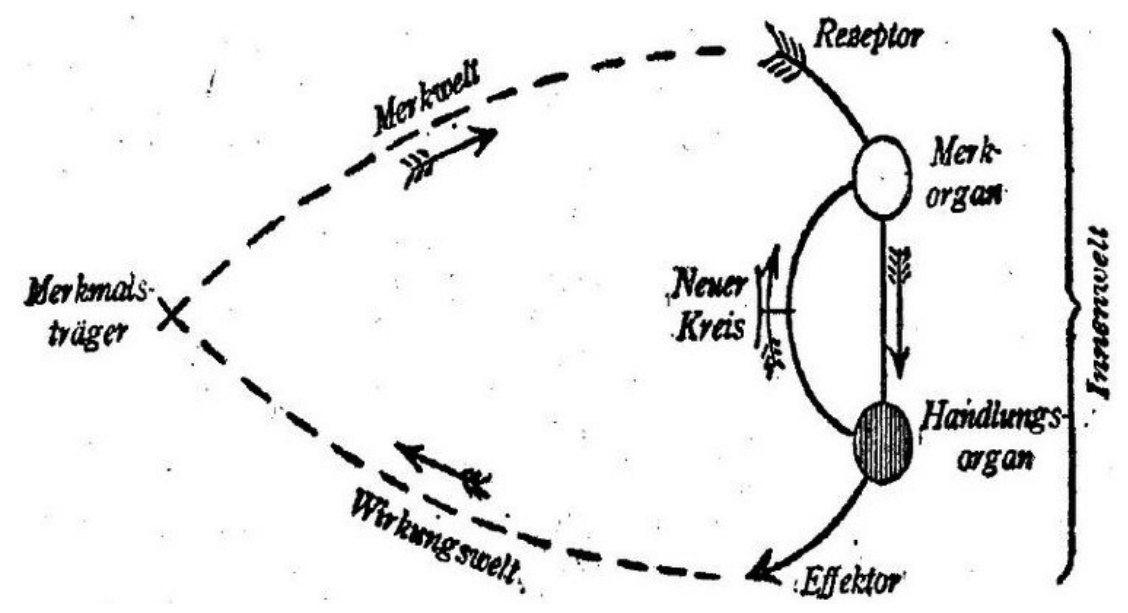

Figure 2. A figure from von Uexküll's Theoretische Biologie. It shows the basic loop, elaborated through a "Neuer Kreis". This "new loop" represents the re-afference mechanism. The rightmost part (drawn, not dashed) is denoted "Innenwelt" (inner-world). It contains the Receptor (Merkorgan), and the Effector (Handlungsorgan). The new loop closes the loop between sensing and acting, predicting the outcome of the action. The left, dashed, part of the figure shows how the loop is closed in a virtual (hence dashed) environment. A hypothetical object (Merkmalsträger) closes the loop between Wirkungswelt and Merkwelt. The hypothetical object is a Ding an sich, it cannot be known (to the agent) apart from the sensorimotor interaction.
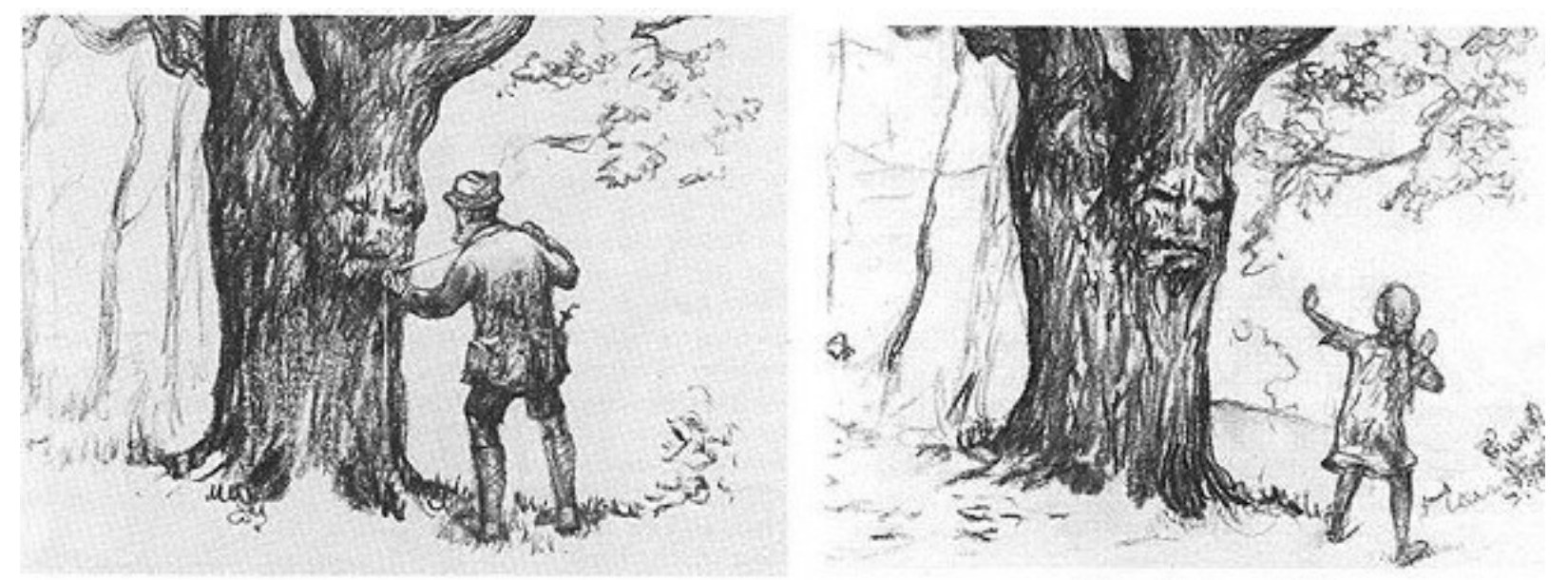

Figure 3. A figure from von Uexküll's Streifzüge durch die Umwelten von Tieren und Menschen (1934). It shows an oak tree as it appears to a ranger and to a little girl. The oak tree is a very different object to these agents because their Umwelts are different. In the book, von Uexküll considers the same oak tree from the perspective of a number of animals. Thus, he shows that "the" oak tree doesn't exist, except as a hypothetical Ding an sich, that is different for any sentient being. 
the scallop's Umwelt in a way that is not immediately obvious to the human observer (with an entirely different Umwelt), one needs to be a (professional or amateur) ethologist to notice such things.

Thus the "Umwelt" is to be distinguished from an "ecological niche". The latter is to be understood as an account of the environment of an animal, in terms of physics. This account will be limited to physical processes that "matter" for the animal. Thus the flux of solar neutrinos does not figure in the account of the ecological niche of your cat. The ecological niche is thus different from the (geographical) environment. An account of the environment is independent of the agents (with various ecological niches) living in it. Gibson's ecological notions apply mostly to the ecological niches, he does not know the Umwelt concept.

It is perhaps not superfluous to remark that the "body" of the agent is (of course) a part of the physical world. It thus appears in the Umwelt too. Other agents and their bodies may also be part of another agent's Umwelt. For instance, your dog is part of your Umwelt. The body/environment distinction is a vague one, that may shift (think of tool use, driving a vehicle, or joining in a dance).

There exist numerous sentient beings (that are agents), many of which are mutually alien. The Umwelts of mutually alien agents are naturally different ${ }^{6}$ (figure 3 ). However, they sometimes overlap, often in unexpected ways. This does not imply that the agents in anyway "communicate". Even so it might mean that their Umwelts significantly overlap though. For instance, consider a spider constructing its first web. It has never caught or eaten a fly. Yet the web's mazes are neatly tuned to fly-size, the mechanical properties of the threads are just right for catching flies, and so forth. Without knowing each other the fly and the spider together "sing a duet" so to speak. The organic world is like a polyphonic music, or perhaps, is like a stage play, where each player only minds his own role, yet the audience experiences a (non-existing) causal nexus of events.

This strongly resembles Leibniz monadology ${ }^{7}$ where the "monads have no windows". In the monadology the apparent interactions are due to a pre-established harmony, a notion that is alien to the contemporary mind. But, of course, the harmony results from the co-evolution of sentient beings on earth. Even the earth itself co-evolves. It is very important to keep this basic fact in mind. No sentient being is an island.

\subsection{The Inner-world}

Sentient beings are "aware". There is something "it is" to be a sentient being, that something is its "inner-world". This aspect of sentience is not at all understood in the scientific sense. Science has no handle on the issue. In this sense, the very term "inner-world" is meaningless. Indeed, at least since the flowering of behaviorism, science has simply designated awareness (or, more usually "consciousness") as at best an epiphenomenon, more often simply considered it as not corresponding to anything existing in the physical world.

Suppose one decides to accept that (some or all, at least yourself, perhaps your spouse, ...) objects are aware. Then what can you say about it? If there is no science on the matter (and you may well agree that there can't be), is it at least possible to come up with some acceptable story? Here "acceptable" will probably mean moving out from the commonly agreed realm of the exact sciences, of course. "Acceptable" means intuitive to you as a sentient being.

It stands to reason that the inner-worlds of organisms are made up of fully idiosyncratic (subjective) experiences. Thus, you will never know what it is like to be a dog or a bat, nor will the dog or bat ever know what it is like to be a human. This applies to you and your neighbor too, but (intuitively) perhaps less so.

Subjective experiences are composed of meanings and qualities. Here "meaning" is intended as "common sense", "gut feeling", and so forth. Some "meanings" are like emotions, projected into the world, like "happy day", or "sad face". Qualities are things like softness, redness, and so forth. Qualities and meanings are not necessarily easy to distinguish from each other. Introspectively, awareness is meaning and quality through and through. You cannot even be aware of anything without it having meaning and/or quality.

As science tells us, physical objects and processes are devoid of any meanings or qualities. As Democrites tells us "by convention hot, by convention cold, but in reality atoms and void". This neatly fits the contemporary account of nature. So how have the meanings and qualities entered awareness?

The only reasonable assumption is that the meanings and qualities are due to prior experiences. Anything else would imply some form of "divine intervention", or "magic". Numerous events are certain to recur again 
and again in the course of the life of an animal. Indeed, without such endless repeats life would be impossible. Thus, it makes some sense to assume that repeated experiences lead to the formation of a "functional tone", typical for that type of event. This would have value to increase the biological fitness of the animal, since the "functional tone" would act as a label for that type of experience, and have predictive value. Such functional tones are superficially similar to the Gibsonian notion of "affordances". However, Gibson ${ }^{3}$ seeks the affordance in the physical objects. For instance, he places the affordance "throwability" in a stone. This evidently makes no sense. Stones may be put to infinite uses, it is impossible to list them all. A stone only becomes "throwable" (and only to you) the moment you intend to use it that way.

Von Uexküll has "objects are always transformed into perceptual cues or perceptual images and invested with a functional tone. This alone makes them into real objects, although no element of the functional tone is actually present in the stimuli". These objects populate the Gegenwelt (counter-world). It is like the agent "projects" meanings and qualities into the world, and can only be aware of the world through these projections. It is a way of simultaneously grasping and creating.

One has to think of the entities in the counter-world perhaps more as of "performances" than as "objects". The agent does not so much "objectify" the world as "toolify" it. Thus all qualities of these "things" are meaningful in terms of perceptual cues and potential interactions. Anything else that the physicist might discover is simply ignored. The thing is a meaning-carrier, and the meaning is imprinted by the agent, rather than found in the world. If an object is used in different ways, it may possess several performance images, which then lend different tones to the same perceptual image. Thus the structure of the counter-world is not in any sense "veridical". No element of the functional tone can be found in the physicist's description. The only right to existence of the counter-world is its subserving fitness. Thus meanings and qualities should not be sought in physical objects or processes. They are part of the very core of the agent, the intentions the agent is capable of having.

Such notions sound similar, but are actually very different from Gibson's notion of "affordance". Notice that Gibson says "The affordance of something does not change as the need of the observer changes. The observer may or may not perceive or attend to the affordance, according to his needs, but the affordance, being invariant, is always there to be perceived. An affordance is not bestowed upon an object by a need of an observer and his act of perceiving it. The object offers what it does because it is what it is" (Gibson 1986: 138-139). In my view, the agent is not (pre-cognitively) interpreting patterns of light in the Gibsonean sense. Rather, it is like it has an "optical user interface" that is entirely idiosyncratic, because of its own making. User interfaces subserve efficacious interactions (thus fitness) because they are not veridical and ignore anything that is irrelevant to the agent's present needs.

\subsubsection{Vision as an "Optical User Interface"}

Visual awareness is perhaps best characterized as an optical user interface. ${ }^{8}$ Its elements are meaningful things, qualities and happenings, for better or worse. These elements do not exist in the physical world. They belong to the inner-world. Yet they are hardcore reality, much like the icons on your computer desktop. They are not in any sense "veridical", but they (through eons of evolution) are forged to increase your fitness (in the Darwinnian sense).

Perhaps surprisingly, even basic frameworks like space and time are just parts of the user interface, and are only there to increase your fitness. There are animals whose inner-worlds lack a spacetime structure, we may know this because their Umwelts lack spacetime references. An animal may even lose spacetime during its life, like the sea squirts, who eat their brain when they switch from a larval stage (a free moving chordate fish), to a sedate, mature existence on some rock. That the spacetime frame of human visual awareness is an idiosyncratic structure, is evident from the fact that a movie sequence scrambled in spacetime, can be made to appear "normal". ${ }^{9}$ In such a case the awareness is coherent, but non-veridical(!) because the "actual scene" is chaotic.

In experimental psychology one encounters strong negative reactions against a notion such as that "visual awareness is to be understood as an optical user interface". The underlying reason is an implicit, but very strong, belief in the "God's Eye View" of reality. 


\subsubsection{Against the God's Eye View of Reality}

The notion of the "God's Eye View" is perhaps best explained through this list of core beliefs:

- there is a unique way things should look. Of course, for there is only one veridical view, which is the way things are perceived by Him;

— it is independent of the observer. Thus perfect perception is fully objective;

- physics is our best way to discover this objective reality. Here I use "physics" in a general sense, including the exact sciences in general. The way the world really is, is the account of the sciences;

- limited anatomy, physiology, or mental capacity yield illusion and error. Error is any deviation from the way the world really is;

— modern Western man comes closest to seeing things as they really are.

I list only major items here. There are plenty more, the "God's Eye View" is an extensive frame of thought. The final item of the list is an extreme form of anthropocentrism that any scientist should be ashamed of. The closest approximation to the God's Eye View is apparently the opinion of a Caucasian male with Harvard or MIT education. Odd as it might seem, this is not even a parody of the silent convictions of the learned community. It works mainly because such convictions usually remain sub-surface.

The first two items of the list are perhaps the worst in terms of their unfortunate influence on main stream thought. They deny the existence of multiple world views, the idea that each agent creates its own reality. The God's Eye View mind-frame is deeply wrong, extremely misleading, and - in my view — not acceptable from the perspective of a honest scientist.

The considerations I discussed earlier lead to a view of human visual perception that strays very far from mainstream convictions. It ignores the (implicit) notion of a GODS EYE VIEW as just silly, it does away with the idea that vision is "inverse optics", that the major brain activity in seeing is bottom up, and so forth, as obviously running counter to the facts. That this is rarely recognized must be due to the fact that these beliefs remain sub-surface so to speak. They all — in various ways - ultimately derive from the belief in the God's Eye View.

The God's Eye View mind-frame has dominated twentieth century psychology, and continues to dominate modern (neuro-)cognitive science. To understand visual awareness as an optical user interface leads to novel ways to study human visual perception, and is likely to open the way to novel applications in various fields of endeavor.

\section{THE HUMAN CONDITION}

Humans are vertebrates that have much in common with mammals in general. This any veterinarian will agree on. The background knowledge of anatomy, physiology, and so forth, of veterinarians and medical doctors is almost identical. In spite of these facts, Homo sapiens remains in many respects a remarkable species. The most important difference that sets man apart from the cattle, is probably the use of language and reflective thought. In this section I discuss a few relevant topics.

\subsubsection{Awareness, cognition, reflective thought, and empathy}

Humans are quantitatively special in their cognitive abilities, and perhaps qualitatively different (from most other species) in their linguistic abilities. Reflective thought is built upon the cognitive system, which is again built upon immediate awareness. Vertebrates and many invertebrates exercise some kind of cognition, albeit in widely differing degrees. But reflective thought seems limited to primates, with Homo sapiens at a considerable remove from any other species. Thus there are huge differences among sentient beings on earth.

In human experience we often notice that "pure awareness", "cognition", and "reflective thought", intermingle in a variety of ways. It is very difficult to pry such layers of experience apart, despite the fact that it is not less evident that they are categorically distinct. 
It is very likely that animals different from Homo sapiens lack anything resembling reflective thought. It is much less clear that animals lack cognition though. In fact, it is evident that vertebrates share a basic cognitive foundation. It is also evident that many vertebrates (especially some mammals and birds) possess remarkable cognitive abilities. Such judgments become increasingly difficult for animals that are more alien to us. It would be next to impossible to measure up the cognitive abilities of fully alien beings.

The Umwelts of related sentient beings may overlap very significantly. Think of a wolf pack, hunting together, or the oxpecker bird, cleaning the teeth of a hippopotamus. The Umwelts of you and your neighbor are (very) similar, that of your dog and you not entirely different (you're both mammals, both vertebrates, ...). This enables a certain degree of intersubjectivity, that is largely absent in the relation of you and an octopus (say). This despite the fact that the octopus (an invertebrate) has an Umwelt that is structurally not less complex than that of a dog. The dog and the octopus are mutual aliens.

Humans are very similar to each other. There exists a high degree of emphatic understanding between humans, based on a neurophysiological substrate that is present from birth, and develops spectacularly during early development. It is this emphatic understanding between humans that enables "experimental phenomenology". It enables intersubjectivity, which makes that "first person accounts" are actually acceptable as objective data. Here we find the possibility to move outside the realm of science (which vetoes first person accounts as "subjective") and build a system of mutual understanding that is hardly less "objective" than science proper, yet allows one to include the inner-world into the inquiry.

In retrospect, even objective science is impossible without the emphatic foundation. So called "objectivity" is operationalized as the common agreement inside peer groups, and a consensus has - in the final instance to be based on emphatic understanding. There is no reason to be ashamed of experimental phenomenology. The whiteness of the Kanizsa triangle ${ }^{10}$ is hardly less a fact than the existence of the Majorana particle. ${ }^{11}$ It is most certainly backed up by a much larger peer group.

\subsubsection{Behaviorism and Ethology}

Behaviorism is a branch of psychology that banishes references to the inner-world. It records behavior in the sense of physical phenomena that may be noticed by studying an agent's body. Any first person reports are ignored as "subjective", and of no scientific value. Modern cognitive science has inherited this stifling dread of subjectivity. First person reports are still considered with great suspicion, and not considered scientifically acceptable. Thus movements in the psychology of the early twentieth century, like the Gestalt schools have hardly found any further development in recent times. Most of cognitive science is really "non-invasive (or dry) physiology".

Yet, in reading modern papers on neuro-cognition one finds that the (indeed, truly objective) data tend to be explained in terms of subjective (first person) reports. This is why the general public is interested in this branch of science in the first place. The public (including academics from fields like philosophy, and so forth) skip the technical, objective stuff, and think of the subjective speculations as the honest results of hard science. Of course, this is foul play! If you want to be a honest behaviorist you should have your cake, and eat it. To "explain" neural activity in terms of awareness, and vice versa, is cheating.

The study of animal behavior is ethology. Ethology objectively studies the world (physics), the environment (more physics), and to some extent the Umwelts (physiology) of animals. Its official founding fathers were Konrad Lorenz, Niko Tinbergen, and Karl von Frisch (Nobel Prize 1972), but they evidently based their work on Jakob von Uexküll's foundation. Ethology also records behavior, and might be understood as the biological analog of behaviorism. But it really goes beyond that. It steers clear of behaviorism because von Uexküll showed how to approach the inner-world through the study of the "counter-world", in essence the study of the structure of the "user interfaces".

To the behaviorist, speech is the movement of air molecules. This is how far objective science carries you, and no further. It is not wrong, but hardly gets at the core of the matter. What there is more to speech belongs to the (human) inner-world. Human life would be impossible without this (non-scientific) "addition".

Thus behaviorism gets you in a rut, it is a dead-end in psychological enquiry. However, there is no reason not to use the methods of ethology on humans. Indeed, that is exactly how one studies human babies, a field that 
has seen great developments in recent times. In case of the human (our own) species one may go well beyond ethology though.

Psychology proper applies indeed singularly to humans. Empathy is what makes it possible, because human beings come with built-in empathic systems. This is why psychology can carry us beyond ethology. It allows one to rely on first person reports, as one cannot in the study of an alien species. This is possible because "objectivity" can be replaced with "shared subjectivity", or "intersubjectivity". This branch of experimental psychology might be denoted "experimental phenomenology".

\subsection{Experimental Phenomenology}

Experimental phenomenology depends upon first person reports that are shared between a number of people. In the best cases virtually any human on earth is likely to agree on the report. Examples are many well known visual illusions. Familiar examples are the Necker-cube and its reversals, the "whiter than white" of the Kanizsa triangle, and so forth. I will concentrate on this type of first person reports here, so called visual proofs.

A visual proof is not properly "scientific" in the commonly accepted sense. Consequently, such things are often frowned upon by the "exact sciences". However, true "objectivity" is an unreachable limit anyway. Martian canals counted as objective science for decades, tachyonic neutrinos for several weeks in 2012, and the Higgs boson for just now (from july 4th 2012 on till who knows?). The community that confirms the "whiter than white" of the Kanizsa triangle is actually much larger than the community that may have an informed view on the existence of the Higgs boson. (Even these would have a hard time to explain the meaning of "existence" in this case.) There is really no reason to rate experimental phenomenology a non-science.

\subsubsection{Visual Proofs}

In a visual proof one simply shows something to an observer, and asks for a first person account of the resulting visual awareness. If the results check with your own impressions, you accept the report as "a (scientific) fact". Of course, it may well be that you can find people who fail to confirm the report. This is not necessarily a problem. In some cases one may actually find an objective cause, as in reports on colors by "color blind" observers who miss a certain retinal photopigment. In other cases one sometimes speaks of specific "soul blindnesses" (aphasias), for which (at least at present) no specific physiological deficit can be found. The fact that the report is not necessarily shared by all people on earth is not to be considered a problem. Of course, a report that is not confirmed by anybody has no interpersonal value.

In humans, visual awareness is something that "simply happens", different from reflective thought, which is something one does. Awareness happens to you, that is to say, the awareness as pure reality is not communicable, you can at best "point to it", and hope for the best. Reflective thought is communicable through language. However, reflective thought is on another ontological level than awareness. Reflective thought is unable to "correct" immediate visual awareness, even if it "knows" for sure that the awareness is "not veridical". Numerous "visual illusions" are the proof of that.

Awareness is pure reality in that it provides the substance for reflective thought, which is at considerable remove from immediate reality. Awareness is immediate reality. Thoughts without substance are void, but awareness without reflective thought is at least something, as our animal friends demonstrate. As Heidegger ${ }^{12}$ has it, a stone has no world, animals have poor worlds, whereas humans are world making.

This has both positive and negative aspects. Reflective thought has driven homo sapiens to embarrassing extremes that find no equivalent in the animal kingdom. It is a potentially dangerous "powertool" that can be wielded in constructive, as well as in destructive ways.

\section{CONCLUSIONS}

I discussed von Uxküll's heritage to some extent, in order to make a case for experimental phenomenology as a valid scientific pursuit in the study of human visual awareness. Visual awareness is of great importance, because it delivers the bulk of real substance to reflective thought. Here "real" has to be understood in a sense different from the exact sciences. Awareness indeed is your immediate reality, but it is not to be understood in terms of physical properties. Awareness is meaning and quality through and through. These meanings and qualities 
are not to be found in the physical world. There one has only the Democritean "atoms and the void". The meanings and qualities are part of the optical user interface. The user interface is very important, even in reflective thought, because it is the major cause of intuitions. Reflective thought is important in drawing logical conclusions, and so forth, but breakthroughs in understanding are invariably due to intuitions. As Picasso once said: "the chief enemy of creativity is good sense". This truth applies to science and art alike. Without the creative nature of the microgenesis of awareness, there can be neither art, nor science.

Experimental phenomenology, as applied to visual awareness, thus is the study of the structure of the optical user interface. Such a study has to depend upon first person reports, rendered "scientific fact" through intersubjectivity. That is to say, the most effective method is by way of visual proofs.

Historically, experimental phenomenology was started by the Gestalt schools of psychology at the end of the nineteenth century. One might make a case for the notion that visual artists had already gathered a wealth of phenomenological understanding over the centuries, though. Although experimental phenomenology is far from dead, it is hardly visible in the contemporary literature. In my view it is about time for a revival.

\section{ACKNOWLEDGMENTS}

I am grateful to Professor de Ridder who paid for my visit to the SPIE meeting.

\section{REFERENCES}

1. Koenderink, J. J., "Vision and Information," in: [Perception beyond Inference: The Information Content of Visual Processes], Albertazzi, L., Van Tonder, G. J., Vishwanath, D., eds., 27-58, MIT Press, Boston MA (2011).

2. Uexküll, J. von, [Theoretische Biologie], Springer, Berlin (1928).

3. Gibson, J. J., [The Ecological Approach to Visual Perception], Houghton Mifflin, Boston MA (1979).

4. Lorenz, K. [Die Rückseite des Spiegels], Piper, München (1973).

5. Holst, E. von, Mittelstaedt, H., "Das Reafferenzprinzip. (Wechselwirkungen zwischen Zentralnervensystem und Peripherie.)," Die Naturwissenschaften 37(20), 464-476 (1950).

6. Uexküll, J. von, [Streifzüge durch die Umwelten von Tieren und Menschen: Ein Bilderbuch unsichtbarer Welten], (Sammlung: Verständliche Wissenschaft, Bd. 21), Springer (mit Kriszat, G.), Berlin (1934).

7. Leibniz, G. W., [La Monadologie], édition établie par E. Boutroux, LGF, Paris (1991, orig. 1714).

8. Hoffman, D. D., "The interface theory of perception," in [Object Categorization: Computer and Human Vision Perspectives], Dickinson, S., Tarr, M., Leonardis, A., Schiele, B., eds., 148-165, Cambridge University Press, Cambridge (2009).

9. Koenderink, J. J., Richards, W. A., Doorn, A. J. van, "Space-time disarray and visual awareness," i-Perception 3(3), 159-162 (2012).

10. Kanizsa, G., "Margini quasi-percettivi in campi con stimolazione omogenea," Rivista di Psicologia 49, 7-30 (1955).

11. Majorana, E., "Teoria simmetrica dellelettrone e del positrone," Nuovo Cimento 14, 171-184 (1937).

12. Heidegger, M., [Sein und Zeit], Niemeyer, Tübingen, 19th ed. (2006, orig. 1927). 